\title{
A Fluorescent Chitosan Hydrogel Detection Platform for Sensitive and Selective Determination of Trace Mercury (II) in Water
}

Received 00th January 20xx Accepted 00th January 20xx

DOI: $10.1039 / \times 0 \times x 00000 x$

www.rsc.org/

\begin{abstract}
Zhigang Geng ${ }^{\mathrm{a}}$, Haimin Zhang ${ }^{\mathrm{a}}$, Qizhong Xiong ${ }^{\mathrm{a}}$, Yunxia Zhang ${ }^{\mathrm{a}}$, Huijun Zhao ${ }^{\mathrm{a}, \mathrm{b}}$ Guozhong Wang* ${ }^{\mathrm{a}}$
In this work, three-dimensional (3D) chitosan hydrogel with superior fluorescent property was successfully fabricated by modifying chitosan fibers with glutaric dialdehyde (GD) via a simple cross-linking approach. The resulting threedimensional fluorescent chitosan hydrogel (3D-FCH) with hydrophilic property exhibited a strong blue fluorescence emission under an excitation wavelength of $337 \mathrm{~nm}$. The fluorescent mechanism of as-synthesized 3D-FCH was investigated and proposed in detail by X-ray photoelectron spectra (XPS) and Fourier transform infrared spectra (FT-IR) techniques. As a solid-phase fluorescent probe, the 3D-FCH was used to determine selectively and sensitively mercury (II) $\left(\mathrm{Hg}^{2+}\right)$ ions in aqueous media. The results demonstrated that a prominent fluorescent quenching at $401 \mathrm{~nm}$ was observed in the presence of $\mathrm{Hg}^{2+}$ with a linear response range of 5.0-50 $\mathrm{nM}$ and an estimated detection of limit of 0.9 $\mathrm{nM}$. The fluorescent quenching mechanism could be ascribed to the strong complexation between $\mathrm{Hg}^{2+}$ and GD fluorophore with the conjugate structure. Moreover, the porous structure of chitosan hydrogel and high adsorption capacity of chitosan fibers in hydrogel could be very favorable for rapid fluorescent determination of $\mathrm{Hg}^{2+}$. This work may pave a new way to develop low-cost fluorescent chitosan hydrogel as solid-phase fluorescent determination platform to replace traditional liquid-phase fluorophores for application in fluorescent detection of heavy metal ions.
\end{abstract}

\section{Introduction}

Nowadays, heavy metal pollution has become a severe public health concern worldwide, thus rapid detection of harmful heavy metal ions in water has been one of the most important issues due to their harm on human and environment. ${ }^{1}$ As one of the most toxic metal ions, mercury accumulates in the organism once ingested and is passed along the food chain. Even at low concentration, it causes irreversible damages such as neurological abnormalities, gingivitis, and tumor formation. ${ }^{2}$ Word Health Organization (WHO) has proposed that the mercury ions level in drinking water cannot exceed $1 \mathrm{ppb}(5.0$

\footnotetext{
a. Key Laboratory of Materials Physics, Centre for Environmental and Energy Nanomaterials, Anhui Key Laboratory of Nanomaterials and Nanotechnology, Institute of Solid State Physics, Chinese Academy of Sciences, Hefei 230031, P.R. China.Email: hmzhang@issp.ac.cn, gzhwang@issp.ac.cn, Tel:+86 55165591973.

${ }^{b .}$ Center for Clean Environmental and Energy, Griffith University, Gold Coast Campus, Queensland 4222, Australia. Address here.

Electronic Supplementary Information (ESI) available: SEM and HRSEM of the chitosan aerogel, The fluorescent emission spectra (excited at $295 \mathrm{~nm}$ ) of the 3D$\mathrm{FCH}$, The XPS spectra of 3D-FCH-(Hg2+) $\chi$, and the detail experiment process for measuring the Quantum Yield of the 3D-FCH. See DOI: 10.1039/x0xx00000x
}

$\mathrm{nM}){ }^{3}$ Accompanying with great increase of public concerns on food and drinking water safety, fluorescent detection method has been widely employed to selectively and sensitively determine $\mathrm{Hg}^{2+}$ ions with low concentrations. To date, varieties of fluorescent materials have been developed for fluorescent detection of $\mathrm{Hg}^{2+}$ in water, such as organic dye molecules, ${ }^{4,5}$ semiconductor quantum dots, ${ }^{6}$ noble metal cluster, ${ }^{7}$ and carbon nanodots ${ }^{8}$. Small organic dye molecules as fluorophores have broken a new path for simple, effective, sensitive, on-site analysis of $\mathrm{Hg}^{2+}$. However, most of dye molecules are not environmentally benign, limiting their fluorescent detection applications. ${ }^{4,5}$ In comparison with organic dye molecules, semiconductor quantum dots and noble metal clusters have been attracted much attention for rapid detection of heavy metal ions due to their high quantum yields, tunable size-dependent excitation and emission properties. However, semiconductor quantum dots (e.g., $\mathrm{CdS},{ }^{9} \mathrm{PbS}^{10}$ ) with high toxicity and noble metal clusters with the disadvantages of high cost and scarcity have been 
the biggest limitation of their practical applications. Recently, carbon nanodots with superior fluorescent property, particularly obtained from low-cost and abundant biomasses (e.g., grass, ${ }^{11}$ pomelo peel, ${ }^{12}$ potatoes, ${ }^{13}$ bamboo leaves ${ }^{14}$ ), have received considerable attention as fluorescent probes for metal ions sensing. But they still suffer from low yield (ever lower to 0.1\%). More importantly, the forementioned fluorescent materials are almost exclusively used in liquid-phase form, possibly unfavourable for practical fluorescent detection devices. Therefore, development of low-cost, high-performance fluorescent materials utilizing in solid-phase form may be more attractive for future miniaturized fluorescent detection devices.

As a natural polymer, chitosan has been regarded as one of the most promising adsorbents for heavy metal ions such as $\mathrm{Cd}^{2+}, \mathrm{Cu}^{2+}, \mathrm{Pb}^{2+}$, and $\mathrm{Hg}^{2+}$ because of strong adsorption capability. Studies have demonstrated that for $\mathrm{Hg}^{2+}$, chitosan as adsorbent exhibits superior adsorption capability. ${ }^{15,16}$ This may give us an inspiration to design and develop chitosan-based fluorescent materials, enabling full utilization of high enriching capability of chitosan material for sensitive determination of $\mathrm{Hg}^{2+}$ with low concentration in water. Moreover, the presence of rich oxygen- and nitrogen-containing function groups in chitosan structure may be very favorable for further modifying fluorophore into chitosan structure frame to form a three-dimensional (3D) solid-phase fluorescent detection platform for selective and sensitive determination of $\mathrm{Hg}^{2+}$ in water.

Herein, we reported a facile approach for the synthesis of a three-dimensional (3D) fluorescent hydrogel based on chitosan fibers via cross-linking glutaric dialdehyde (GD) fluorophores at room temperature. For the first time, we demonstrated that the fluorescent intensity of the 3D-FCH can be effectively quenched by
$\mathrm{Hg}^{2+}$ in a highly selective and sensitive manner, which can be used to directly determine low concentrations of $\mathrm{Hg}^{2+}$ in aqueous media with a linear response range of 5.0-50 nM and an estimated detection of limit of $0.9 \mathrm{nM}$.

\section{Experimental}

\section{Materials}

Chitosan and Quinine sulfate were purchased from the Aladdin. GD, Acetic Acid, Mercury standard solution, $\mathrm{FeCl}_{2} \cdot 4 \mathrm{H}_{2} \mathrm{O}, \mathrm{FeCl}_{3} \cdot 6 \mathrm{H}_{2} \mathrm{O}, \mathrm{CuCl}_{2} \cdot 2 \mathrm{H}_{2} \mathrm{O}, \mathrm{Co}\left(\mathrm{NO}_{3}\right)_{2} \cdot 6 \mathrm{H}_{2} \mathrm{O}$, $\mathrm{Pb}\left(\mathrm{NO}_{3}\right)_{2}, \mathrm{AgNO}_{3}, \mathrm{Cd}\left(\mathrm{NO}_{3}\right)_{2} \cdot 4 \mathrm{H}_{2} \mathrm{O}, \mathrm{MnCl}_{2} \cdot 6 \mathrm{H}_{2} \mathrm{O}, \mathrm{ZnCl}_{2}$ and $\mathrm{Hg}\left(\mathrm{NO}_{3}\right)_{2}$ were purchased from Sinopharm Chemical Reageat Co. Ltd. $\mathrm{Ca}\left(\mathrm{NO}_{3}\right)_{2} \cdot 4 \mathrm{H}_{2} \mathrm{O}$ and $\mathrm{Ni}\left(\mathrm{NO}_{3}\right)_{2} \cdot 6 \mathrm{H}_{2} \mathrm{O}$ were purchased from Tianjin Guangfu Fine Chemical Research Institute. The deionized (DI) water was produced using a Millpore Milli-Q grade, with a resistivity of 18.5 $\Omega . \mathrm{cm}^{-1}$. All chemicals were used without further purification.

\section{Preparation of three-dimensional (3D) fluorescent chitosan hydrogel (3D-FCH)}

$0.5 \mathrm{~g}$ of chitosan was first dispersed into $50 \mathrm{~mL}$ of DI water, and then the mixture was transferred into a $100-\mathrm{mL}$ beaker, $0.2 \mathrm{~mL}$ of Acetic Acid was dropwise added into the above solution. After several hours of reaction under stirring, the solution becomes pellucid, and then $0.6 \mathrm{~mL}$ of GD was quickly added into the above solution. The 3DFCH was finally obtained by stirring at room temperature for half an hour. The obtained 3D-FCH was subsequently washed with adequate DI water and then collected by freeze drying technique for further use.

\section{Characterizations}

The products were characterized by various techniques. The morphology and structure of the chitosan aerogel were analyzed on a Sirion 200 FE-SEM (Japan) at an 
accelerating voltage of $10 \mathrm{kV}$. The fluorescence measurements were performed using an EI-FLS920 fluorescence spectrophotometer (UK) equipped with specific size of 3D-FCH sheet. The UV-vis optical absorption spectra were recorded on a UV-2550 optical spectrophotometer (Japan). To obtain composition information, the FT-IR spectra were measured on a Nicolet-Nexus FT-IR spectrometer (USA) with the $\mathrm{KBr}$ pellet technique ranging from $500 \mathrm{~cm}^{-1}$ to $3600 \mathrm{~cm}^{-1}$ at room temperature. The XPS spectra were recorded on an ESCALAB 250 by Thermo-VG Scientific. The concentrations of $\mathrm{Hg}^{2+}$ were demarcated with Mercury standard solution by ICP6300 (ThermoFisher Scientific. USA).

\section{Results and discussion}
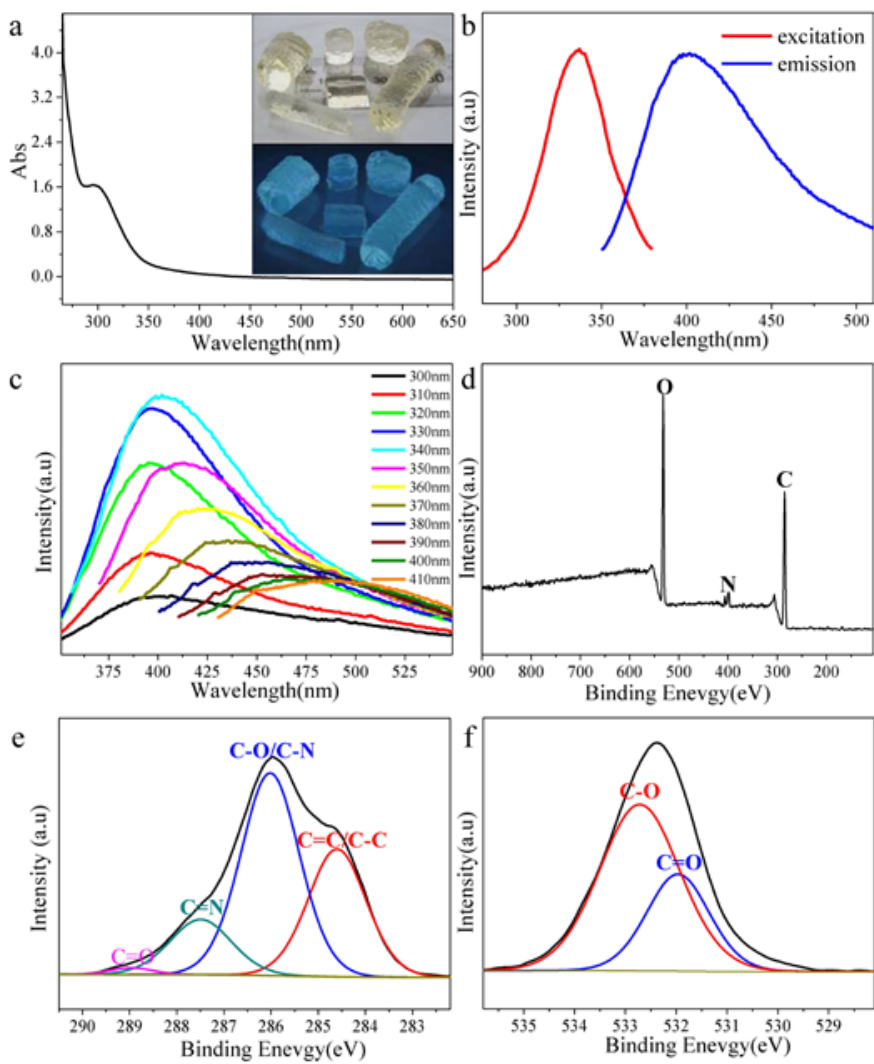

Figure 1. (a) UV-vis absorption (black line) spectrum of the 3D-FCH. Inset: the photograph of 3D-FCH under sunlight (top) and UV light (365 nm) (bottom); (b) Fluorescent excitation and emission spectra $\left(\lambda_{\text {ex }}=337 \mathrm{~nm}, \lambda_{\text {em }}\right.$ $=401 \mathrm{~nm}$ ); (c) Fluorescent emission spectra of the 3D-FCH under different excitation light; (d) XPS of the chitosan aerogel; $\mathrm{C}_{1 \mathrm{~s}}\left(\mathrm{e}\right.$ ) and $\mathrm{O}_{1 \mathrm{~s}}$ (f) spectra of chitosan aerogel.
Through cross-linking GD with chitosan fibers, the 3D-FCH was successfully fabricated in this work. As shown in Figure S1 (ESI $\dagger$ ), the freeze-dried chitosan aerogel possessed well-defined and interconnected 3D porous network structure constructed by chitosan sheets composed of chitosan fibers. As shown in the top inset of Figure 1a, the obtained chitosan hydrogels are yellowish, transparent and clear under sunlight. Importantly, the 3DFCH exhibits a further processable property (hydrogels with different shapes and sizes can be readily obtained), indicating the chitosan hydrogel possessing high mechanical stability and workability. This is critically important for its practical fluorescent detection application in the form of solid phase. When 3D-FCH with different shapes and sizes was irradiated under UV light (main wavelength of $365 \mathrm{~nm}$ ), all hydrogels exhibit obviously blue color (bottom inset in Figure 1a), indicating the chitosan hydrogel with superior fluorescent property. Figure 1a shows the UV-vis absorption spectra of 3D-FCH As shown, the optical absorption peak of 3D-FCH was observed in the UV region with a maximum absorption at $295 \mathrm{~nm}$, possibly attributed to the $n-\pi^{*}$ transition of the $\mathrm{C}=\mathrm{N}, \mathrm{C}=\mathrm{O}$ band and $\pi-\pi^{*}$ transition of the conjugated $\mathrm{C}=\mathrm{C}$ band. On excitation at the absorption band of $295 \mathrm{~nm}$, the 3D-FCH shows a strong emission peak at $395 \mathrm{~nm}$ with a stoke shift of $100 \mathrm{~nm}$ (Figure S2, ESI†). The quantum yield of the 3D-FCH was measured to be about 7.9\% using the absorbance and integrated emission intensity of quinine sulfate in $0.1 \mathrm{~mol} / \mathrm{L} \mathrm{H}_{2} \mathrm{SO}_{4}$ as a reference $(\mathrm{ESI} \dagger){ }^{17}$ Figure 1b shows the photoluminescence (PL) excitation and emission spectra of 3D-FCH. As shown, the 3D-FCH can be excited by wavelengths between 330 and $340 \mathrm{~nm}$. When the excitation wavelength was set at $337 \mathrm{~nm}$, a strong PL emission peak centered at $\sim 401 \mathrm{~nm}$ can be apparently observed. Like most fluorescent materials (e.g., graphene quantum dots ${ }^{18}$, carbon quantum dots ${ }^{17,19}$ ), the $3 \mathrm{D}-\mathrm{FCH}$ also exhibits a unique phenomenon of $\lambda_{\text {ex }}$-dependent $\lambda_{\text {em }}$ fluorescent behavior. The emission peak of the 3D-FCH 
was shifted to a higher wavelength with the increase of the excitation wavelength (from 300 to $410 \mathrm{~nm}$ ), as shown in Figure 1c. The plausible reason of the $\lambda_{\text {ex }}$-dependent $\lambda_{\text {em }}$ phenomenon for quantum dots is their different sizes distribution $^{20}$ and surface defects ${ }^{18,21}$, while in our system, the possible reason of $\lambda_{\text {ex }}$-dependent $\lambda_{\mathrm{em}}$ fluorescent behavior may be due to the presence of different surface energy traps caused by rich functional groups on the surface of 3D-FCH. This may result in a series of emissive traps between $\pi-\pi^{*}$ and $n-\pi^{*}$ of $\mathrm{C}=\mathrm{C}$ and $\mathrm{C}-\mathrm{O}, \mathrm{C}=\mathrm{N}^{18,21}$ To further verify this viewpoint, the freeze-dried chitosan aerogel was characterized by XPS for analyzing the surface composition. The XPS spectrum (Figure. 1d) shows three peaks at 284.0, 400.0 and $530.6 \mathrm{eV}$, which are attributed to $\mathrm{C}_{1 \mathrm{~s}}(59.8 \%), \mathrm{N}_{1 \mathrm{~s}}(6.4 \%)$ and $\mathrm{O}_{1 \mathrm{~s}}(33.8 \%)$, respectively. The high resolution $C_{1 s}$ spectrum (Figure 1e) can be deconvoluted into several single peaks, corresponding to $\mathrm{C}=\mathrm{C} / \mathrm{C}-\mathrm{C}(284.5 \mathrm{eV}), \mathrm{C}-\mathrm{N} / \mathrm{C}-\mathrm{O}$ (286.2 $\mathrm{eV}), \mathrm{C}=\mathrm{N}(287.5 \mathrm{eV})$ and $\mathrm{C}=\mathrm{O}(288.8 \mathrm{eV})$ functional groups. $^{22,23}$ The high resolution $\mathrm{O}_{1 \mathrm{~s}}$ spectrum (Figure 1f) exhibits two peaks at 531.7 and $533.0 \mathrm{eV}$, which are attributed to $\mathrm{C}=\mathrm{O}$ and $\mathrm{C}-\mathrm{O}$ groups, ${ }^{23}$ respectively. These results are consistent with the reported results of fluorescent materials with different surface energy traps caused by rich functional groups on the surface.

To gain an insight into the photoluminescence mechanism of 3D-FCH, the FT-IR experiments were performed in this work. The FT-IR spectrum of pristine chitosan (curve A in Figure 2a) shows the characteristic absorption band of -OH stretching vibration mode locating at about $3300 \mathrm{~cm}^{-1}$, the peaks at about 1410 and $1080 \mathrm{~cm}^{-1}$ attributing to the stretching vibration of $-\mathrm{CH}_{2}-$, the characteristic absorption bands of - $\mathrm{CH}$ stretching at 2937 $\mathrm{cm}^{-1}$ and $2875 \mathrm{~cm}^{-1}$, and the peak at $1539 \mathrm{~cm}^{-1}$ of $-\mathrm{NH}_{2}$ stretching mode. Compared with pristine chitosan, the obtained chitosan aerogel (curve B in Figure 2a) exhibits the characteristic absorption bands of a conjugate structure stretching vibration at $1647 \mathrm{~cm}^{-1}$, which is corresponding to the stretching vibration of $-\mathrm{C}=\mathrm{C}-\mathrm{N}=\mathrm{C}-.^{24,25}$ The above results were further confirmed by high resolution $\mathrm{N}_{1 \mathrm{~s}}$ XPS spectrum of the chitosan aerogel. Figure $2 b$ shows the high resolution $\mathrm{N}_{1 \mathrm{~s}}$ spectrum of pristine chitosan (curve $\mathrm{A}$ ) and chitosan aerogel (curve B). Besides the main peaks centered at about $399.2 \mathrm{eV}$ and $401.6 \mathrm{eV}$ corresponding to $\mathrm{C}-\mathrm{N}$ and $\mathrm{N}-\mathrm{H}$ respectively, the chitosan hydrogel displays an obvious characteristic peak at $400.5 \mathrm{eV}$, which is ascribed to the conjugate structure of $\mathrm{C}-\mathrm{N}=\mathrm{C}^{25}$. The above results propose that the photoluminescence mechanism of the 3D-FCH may be ascribed to the conjugate structures of a new fluorophore via a simple cross-linking approach, similar with the reported fluorescent dye molecules.
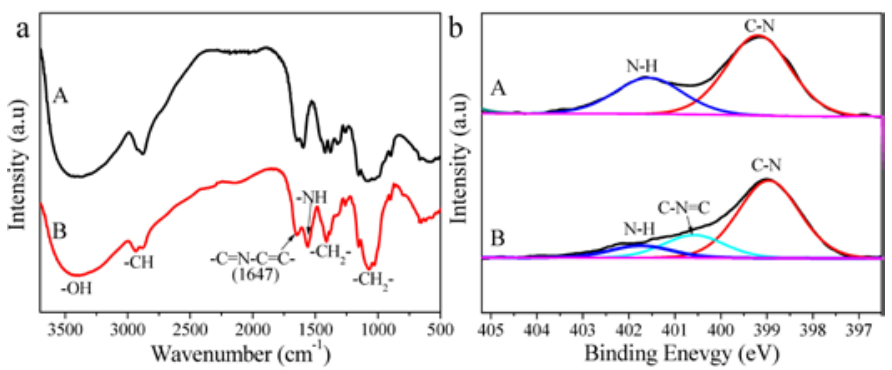

Figure 2. (a) FT-IR spectra of the pristine chitosan (A) and chitosan aerogel (B); (b) $\mathrm{N}_{1 \mathrm{~s}}$ spectra of the pristine chitosan (A) and chitosan aerogel (B).

To date, almost all reports are exclusively using liquid-phase formed fluorophores for fluorescent detection of heavy metal ions in aqueous media. ${ }^{26,27}$ To the best of our knowledge, there are no reports on using solid-phase fluorescent hydrogel for selective and sensitive determination of heavy metal ions in aqueous media. In this work, the 3D-FCH was used as fluorescent detection platform to highly selective and sensitive determine low concentrations of $\mathrm{Hg}^{2+}$ in aqueous media. Usually, the fluorescent intensity of quantum dots/fluorescent dyes was correlative with their concentration. However, the fluorescent intensity of solid-phase fluorophore is highly dependent on the thickness fluorescent material. Figure 3a shows the dependence of fluorescent intensity on the thickness of 3D-FCH. As shown, the fluorescent intensity initially increases with the thickness of 3D-FCH from 0.05 $\mathrm{cm}$ to $0.1 \mathrm{~cm}$, but gradually decreases further increasing 
the 3D-FCH thickness under the given experimental conditions. The maximum fluorescent intensity can be achieved when the thickness of 3D-FCH is $0.1 \mathrm{~cm}$, which may be beneficial for improving detection sensitivity of 3D-FCH. The thickness-dependent fluorescent intensity may be due to certain thickness of hydrogel with the maximum irradiation depth at a given excitation wavelength. To ensure measurement accuracy and reproducibility, the same sized 3D-FCH with a thickness of $0.1 \mathrm{~cm}$ were adopted for subsequent experiments. The response time for fluorescent quenching is a very important parameter to evaluate fluorescent detection performance of the fluorescent probes. Figure 3b shows the time-dependent fluorescent intensity of the 3D-FCH with a thickness of $0.1 \mathrm{~cm}$ quenched with $10 \mathrm{nM} \mathrm{Hg}^{2+}$ excited at $337 \mathrm{~nm}$. As shown, the introduction of $\mathrm{Hg}^{2+}$ leads to a rapid decrease in the fluorescent intensity during the initial $30 \mathrm{~min}$. Subsequently, the fluorescent intensity gradually levels off at relatively stable values with a further increased quenching time. For better accuracy and reproducibility, all fluorescent intensities of the samples are measured after $0.5 \mathrm{~h}$ reaction for subsequent experiments. It is believed that the 3D porous network structure of the chitosan hydrogel significantly improves mass transfer, enabling full utilization of high adsorption property of chitosan fibers for $\mathrm{Hg}^{2+}$ ions, thus resulting in rapid response of fluorescent quenching. Further, we also investigated the solution $\mathrm{pH}$ influence on fluorescent intensity of the 3D-FCH. It was found that no obvious change in fluorescent intensity was observed within the $\mathrm{pH}$ range from 3 to 9 (Figure 3c), indicating high structure stability of the 3D-FCH in wide $\mathrm{pH}$ range. This is critically important for practical sensing applications.

For a sensitivity study, different concentrations of $\mathrm{Hg}^{2+}$ in the range from 0 to $50 \mathrm{nM}$ were investigated. Figure 4a shows a gradual decrease in fluorescent intensity at $401 \mathrm{~nm}$ with increasing $\mathrm{Hg}^{2+}$ concentration, revealing that the sensing system is sensitive to $\mathrm{Hg}^{2+}$ concentration under given experimental conditions. The fluorescent quenching data is further analyzed by the Stern-Volmer equation. $^{28}$
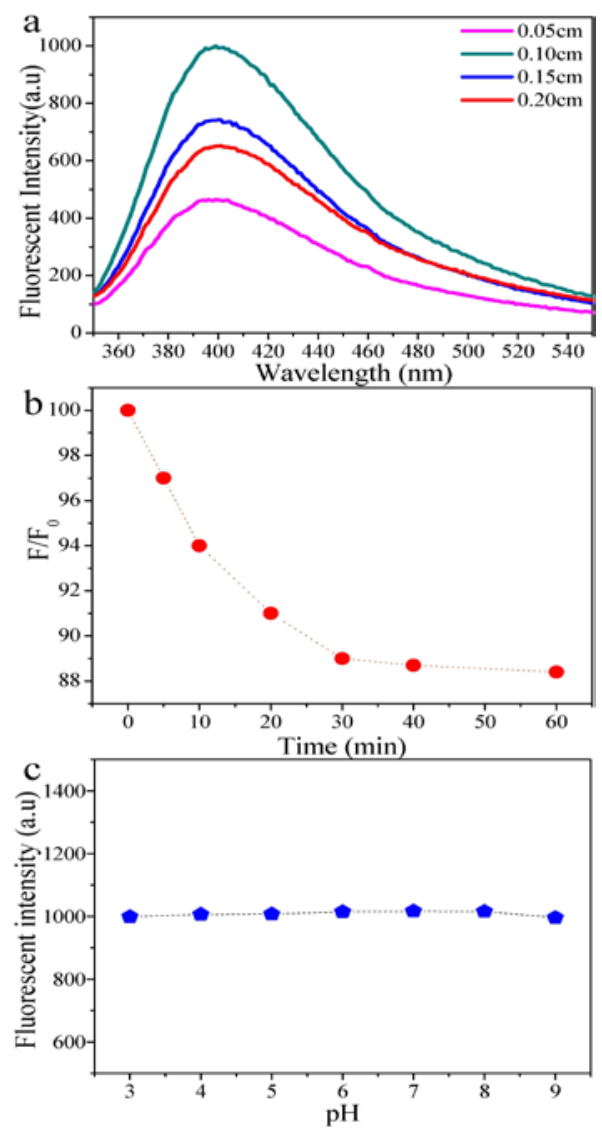

Figure 3. (a) Fluorescent intensity of the 3D-FCH with different thickness; (b) Relationship of the intensity of the fluorescence spectra and the response time for the fluorescent probes in the $\mathrm{Hg}^{2+}$ solution with the concentration of $10 \mathrm{nM}$; (c) Effect of the $\mathrm{pH}$ (3-9) on 3D-FCH fluorescence, (all of the experiment were excited at $337 \mathrm{~nm}$ ).

$$
F_{0} / F-1=K_{\mathrm{sv}} C
$$

Where the $F_{0}$ and $F$ is the fluorescent intensity of the 3D-FCH at $401 \mathrm{~nm}$ in the absence and presence of $\mathrm{Hg}^{2+}$ respectively, $K_{\mathrm{sv}}$ is the Stern-Volmer quenching constant, $C$ is the analyte $\left(\mathrm{Hg}^{2+}\right)$ concentration, the Stern-Volmer plot shown in Figure 4b does not fit a linear Stern-Volmer equation in the investigated concentration range. While the correlation coefficients $\left(R^{2}\right)$ is 0.996 for determining $\mathrm{Hg}^{2+}$ over the concentration range of 5.0 to $50 \mathrm{nM}$ (1 to $10 \mathrm{ppb}$ ), the limit of detection (LOD) is estimated to be $0.9 \mathrm{nM}$ at a signal-to-noise ratio of 3 , which is much lower than the reported results using liquid-phase fluorophore system 
(Table 1) ${ }^{29 \sim 36}$. The achieved linear detection range using solid-phase fluorescent chitosan hydrogel in this work is believed to be applicable for sensitive detection of $\mathrm{Hg}^{2+}$ in drinking water (maximum permitted level of $10 \mathrm{nM}$, United States Environmental Protection Agency) and wastewater (below 50 nM, China).
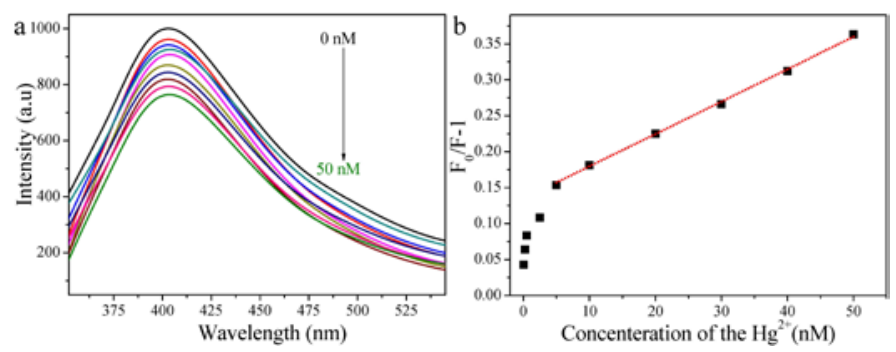

Figure 4. (a) Fluorescent spectra of the $3 \mathrm{D}-\mathrm{FCH}$ in the presence of different $\mathrm{Hg}^{2+}$ concentration for $0.5 \mathrm{~h}$ (from top to bottom: blank, 0.05, 0.25, 0.5, 2.5, $5,10,20,30,40$, and $50 \mathrm{nM}, \mathrm{pH}=5.7-5.9$, excited at $337 \mathrm{~nm}$ ); (b) Plots of the values of $\left(\mathrm{F}_{0} / \mathrm{F}\right)-1$ at the $401 \mathrm{~nm}$ versus the concentrations of $\mathrm{Hg}^{2+}$.

Table 1. Comparison of the sensitivities and linear ranges of different fluorescent dye molecules and its derivative for $\mathrm{Hg}^{2+}$ detection.

\begin{tabular}{cccc}
\hline Probe & Linear range (nM) & LOD (nM) & Reference \\
\hline squaraine dye & $1 \times 10^{3}-1 \times 10^{4}$ & 13 & 29 \\
Glyoxylic acid - rhodamine B & $5 \times 10^{3}-2 \times 10^{5}$ & 1000 & 30 \\
Hydroxymethylpridine - rhodamine B & $100-5 \times 10^{3}$ & 15.7 & 31 \\
thioether linked squaraine-aniline dyads & $30-1.8 \times 10^{3}$ & 6.6 & 32 \\
Piperonal - rhodamine B & $0-1 \times 10^{3}$ & 12 & 33 \\
oligodeoxyribonucleotide & $40-100$ & 40 & 34 \\
4-(Vinyloxy)benzaldehyde-TCF & $0-3 \times 10^{3}$ & 10 & 35 \\
BODIPY & $1.5 \times 10^{3}-1.4 \times 10^{4}$ & 530 & 36 \\
3D-FCH & $5-50$ & 0.9 & This work
\end{tabular}

The selectivity is another important parameter to evaluate the applicability of a fluorescent detection method. Therefore, we examined the effect of common cations on fluorescent peak intensity of 3D-FCH in the presence of $\mathrm{Hg}^{2+}$. Figure 5a shows the relative fluorescent intensities in the presence of common cations under the same experimental conditions, including $\mathrm{Pb}^{2+}, \mathrm{Cu}^{2+}, \mathrm{Ni}^{2+}, \mathrm{Fe}^{3+}$, $\mathrm{Fe}^{2+}, \mathrm{Mn}^{2+}, \mathrm{Zn}^{2+}, \mathrm{Cd}^{2+}, \mathrm{Ag}^{+}$and $\mathrm{Hg}^{2+}$. As shown, an important decrease of fluorescent intensity was observed in the presence of $\mathrm{Hg}^{2+}$, while no obvious decrease in fluorescent intensity was found for other cations. Furthermore, the selectivity of the fluorescent detection system in the presence of all possible interference cations (e.g., $\mathrm{Fe}^{2+}, \mathrm{Cu}^{2+}, \mathrm{Ni}^{2+}, \mathrm{Co}^{2+}, \mathrm{Cd}^{2+}, \mathrm{Mn}^{2+}, \mathrm{Pb}^{2+}, \mathrm{Zn}^{2+}$ and $\mathrm{Ca}^{2+}$ ) were also evaluated. As shown in Figure 5b, the developed method in this work can still detect selectively and sensitively $\mathrm{Hg}^{2+}$ in the presence of all possible interference cations (the concentration of each cation in the mixture is $5.0 \mathrm{ppm}$, while the concentration of $\mathrm{Hg}^{2+}$ is 0.05 ppm). The excellent selectivity could be attributed to a stronger interaction between the fluorophore of conjugate structure and $\mathrm{Hg}^{2+}$ than other metal ions. Two possibilities for the fluorescent quenching in our system can be proposed as follows: 1 ) interaction of $\mathrm{Hg}^{2+}$ ions with GD fluorophore to form a new complexation; 2) oxidation of the fluorophore on the 3D-FCH or reduction of $\mathrm{Hg}^{2+}$ ions by 3D-FCH. Figure S3 (ESI $\dagger$ ) shows the high resolution XPS Hg4f spectrum of chitosan aerogel after adsorbing $\mathrm{Hg}^{2+}$ with a concentration of $50 \mathrm{ppb}$ for $0.5 \mathrm{~h}$. As shown, two peaks centered at $101.4 \mathrm{eV}$ and $105.5 \mathrm{eV}$ can be clearly observed. It is known that the binding energy of Hg4f for $\mathrm{Hg}^{0}$ appears at $100.01 \mathrm{eV}$ and $103.5 \mathrm{eV}$, while the binding energy of $\mathrm{Hg}^{2+}$ appears at $101.0 \mathrm{eV}$ and $105.1 \mathrm{eV}$, respectively. Therefore, it can be concluded that the two peaks centered at $101.4 \mathrm{eV}$ and $105.5 \mathrm{eV}$ may be assigned to the shift of $0.4 \mathrm{eV}$ towards higher binding energy of $\mathrm{Hg}^{2+}$ in $3 \mathrm{D}-\mathrm{FCH}-\left(\mathrm{Hg}^{2+}\right)_{\chi}$, indicating the formation of a covalent bond between an empty orbital of $\mathrm{Hg}^{2+}$ and $\pi$ electrons of the fluorophore. ${ }^{37}$ Hence, these results adequately demonstrate that a strong complexation between $\mathrm{Hg}^{2+}$ and the fluorophore can be produced, which provokes an effective electron transfer process for fluorescent quenching of the 3D-FCH.

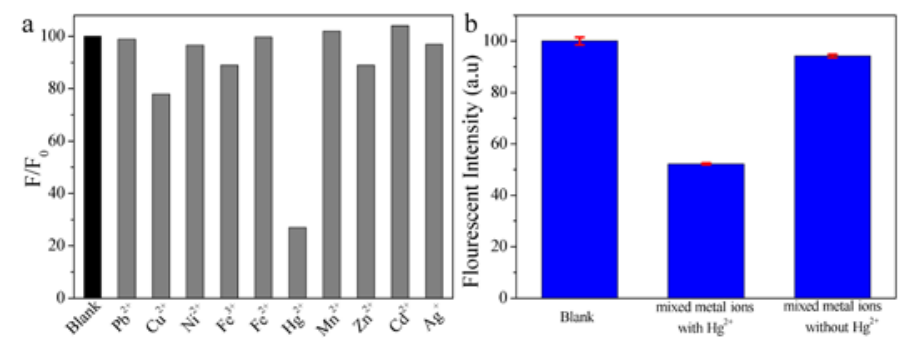


Figure 5. (a) Relative fluorescent intensity of the 3D-FCH of the blank and solutions containing different metal ions with the concentration of $10 \mathrm{mM}$ (excitation at $337 \mathrm{~nm}, \mathrm{~F}_{0}$ and $\mathrm{F}$ are fluorescent intensities at $401 \mathrm{~nm}$ in the absence and presence of ions, respectively); (b) Selectivity of the fluorescent detection system in the presence of all possible interference cations, the fluorescent intensity was normalized by the $F_{0}$.

In order to evaluate the applicability of 3D-FCH for detecting $\mathrm{Hg}^{2+}$ in real water samples, a standard addition method was applied to test water samples from the Dong Pu reservoir of HeFei, AnHui province, China, this water sample was filtered through a $0.22 \mu \mathrm{m}$ membrane and then centrifuged at $12000 \mathrm{rpm}$ for $15 \mathrm{~min}$. The resultant water samples were spiked with standard solutions containing the concentration of $\mathrm{Hg}^{2+}$ is $2.0 \mathrm{ppb}$, the recoveries of the spiked water sample is $105 \%$. These results imply that the developed method here is likely to be capable of practically useful $\mathrm{Hg}^{2+}$ detection in drink water upon further development.

\section{Conclusions}

3D fluorescent chitosan hydrogel (3D-FCH) was successfully fabricated by using GD as cross-linker. The resulting 3D-FCH exhibited superior fluorescent property, achieving a detection limit of $0.9 \mathrm{nM}$ with an analytical linear range up to $50 \mathrm{nM}$ for selective and sensitive determination of $\mathrm{Hg}^{2+}$ in aqueous media. The 3D porous structure of chitosan hydrogel is very beneficial for mass transfer, enabling full utilization of high adsorption capability of chitosan fibers in hydrogel frame, resulting in rapid fluorescent quenching response. Our findings pave the way for developing low-cost and solid-phase fluorescent hydrogel as fluorescent probe for selective and sensitive determination of harmful heavy metal ions in aqueous media.

\section{Acknowledgements}

This work was financially supported by the Natural Science Foundation of China (Grant No. 51472246 and 51072199), the Strategic Priority Research Program of the Chinese Academy of Sciences (Grant No. XDA09030200), and the CAS/SAFEA International Partnership Program for Creative Research Teams of Chinese Academy of Sciences, China, and the CAS Pioneer Hundred Talents Program.

\section{Notes and references}

1 C. T. Driscoll, R. P. Mason, H. M. Chan, D. J. Jacob, N. Pirrone, Environ. Sci. Technol., 2013, 47, 4967-4983.

2 Y. Z. Wang, H. Yang, M. Pschenitza, R. Niessner, Y. Li, D. Knopp, A. P. Deng, Anal. Bioanal. Chem., 2012, 403, 25192528.

3 A. Gupta, S. R. Vidyarthi, N. Sankararamakrishnan, J. Hazard. Mater., 2014, 274, 132-144.

4 L. Zhang, H. X. Chang, A. Hirata, H. K. Wu, Q. K. Xue, M. W. Chen, ACS Nano, 2013, 7, 4595-4600.

5 V. Bhalla, R. Tejpal, M. Kumar, Sens. Actuator B-Chem., 2010, 151, 180-185.

6 A. Ben Moshe, D. Szwarcman, G. Markovich, ACS Nano, 2011 5, 9034-9043.

7 B. Adhikari, A. Banerjee, Chem. Mat., 2010, 22, 4364-4371.

8 A. Gupta, A. Chaudhary, P. Mehta, C. Dwivedi, S. Khan, N. C. Verma, C. K. Nandi, Chem. Commun., 2015, 51, 10750-10753.

9 D. W. Huang, C. G. Niu, X. Y. Wang, X. X. Lv, G. M. Zeng, Anal. Chem., 2013, 85, 1164-1170.

10 Y. X. Yu, R. Zhang, K. X. Zhang, S. Q. Sun, J. Nanosci. Nanotechnol., 2012, 12, 2783-2790.

11 S. Liu, J. Q. Tian, L. Wang, Y. W. Zhang, X. Y. Qin, Y. L. Luo, A. M. Asiri, A. O. Al-Youbi, X. P. Sun, Adv. Mater., 2012, 24, 2037-2041.

12 W. B. Lu, X. Y. Qin, S. Liu, G. H. Chang, Y. W. Zhang, Y. L. Luo, A. M. Asiri, A. O. Al-Youbi, X. P. Sun, Anal. Chem., 2012, 84, 5351-5357.

13 J. Y. Xu, Y. Zhou, S. X. Liu, M. T. Dong, C. B. Huang, Anal. Methods, 2014, 6, 2086-2090.

14 Y. S. Liu, Y. A. Zhao, Y. Y. Zhang, Sens. Actuator B-Chem., 2014, 196, 647-652.

15 C. Penichecovas, L. W. Alvarez, W. Arguellesmonal, J. Appl. Polym. Sci., 1992, 46, 1147-1150.

16 L. M. Zhou, Z. R. Liu, J. H. Liu, Q. W. Huang, Desalination, 2010, 258, 41-47.

17 Y. H. Yang, J. H. Cui, M. T. Zheng, C. F. Hu, S. Z. Tan, Y. Xiao, Q. Yang, Y. L. Liu, Chem. Commun., 2012, 48, 380-382.

18 S. J. Zhu, J. H. Zhang, S. J. Tang, C. Y. Qiao, L. Wang, H. Y. Wang, X. Liu, B. Li, Y. F. Li, W. L. Yu, X. F. Wang, H. C. Sun, B. Yang, Adv. Funct. Mater., 2012, 22, 4732-4740.

19 Y. Q. Dong, C. Q. Chen, J. P. Lin, N. N. Zhou, Y. W. Chi, G. N. Chen, Carbon, 2013, 56, 12-17.

20 C. Y. Chang, J. Peng, L. N. Zhang, D. W. Pang, J. Mater Chem., 2009, 19, 7771-7776

21 M. Li, S. K. Cushing, X. J. Zhou, S. W. Guo, N. Q. Wu, J. Mater. Chem., 2012, 22, 23374-23379.

22 Y. Zheng, Y. Jiao, L. Ge, M. Jaroniec, S. Z. Qiao, Angew. Chem.-Int. Edit., 2013, 52, 3110-3116.

23 W. Li, Z. H. Zhang, B. A. Kong, S. S. Feng, J. X. Wang, L. Z. Wang, J. P. Yang, F. Zhang, P. Y. Wu, D. Y. Zhao, Angew. Chem.-Int. Edit., 2013, 52, 8151-8155.

24 K. Wang, Y. Xun, Z. P. Guo, J. Y. Xu, Y. Chen, Carbohydr. Polym., 2014, 102, 699-707.

25 H. Zhang, J. B. Fei, X. H. Yan, A. H. Wang, J. B. Li, Adv. Mater., 2015, 25, 1193-1204. 
26 Z. S. Qian, X. Y. Shan, L. J. Chai, J. R. Chen, H. Peng, Biosens. Bioelectron., 2015, 68, 225-231.

27 Z. Y. Zhang, S. Z. Lu, C. M. Sha, D. M. Xu, Sens. Actuator BChem., 2015, 208, 258-266.

28 Y. F. Long, D. L. Jiang, X. Zhu, J. X. Wang, F. M. Zhou, Anal. Chem., 2009, 81, 2652-2657.

29 N. Y. Fu, Y. Q. Chen, J. Fan, G. M. Wang, S.Y. Lin, Sens. Actuator B-Chem., 2014, 203, 435-443.

30 X. Zhang, Y. Y. Zhu, Sens. Actuator B-Chem., 2014, 202, 609614.

31 J. W. Hu, Z. J. Hu, Y. Cui, X. J. Zhang, H. W. Gao, K. Uvdal, Sens. Actuator B-Chem., 2014, 203, 452-458.

32 H. J. Zhu, Y. H. Lin, G. M. Wang, Y. Q. Chen, X. H. Lin, N. Y. Fu, Sens. Actuator B-Chem., 2014, 198, 201-209.

33 J. L. Zhang, Y. M. Zhou, W. P. Hu, L. Zhang, Q. Huang, T. S. Ma, Sens. Actuator B-Chem., 2013, 183, 290-296.

34 A. Ono, H. Togashi, Angew. Chem.-Int. Edit., 2004, 43, 43004302.

35 B. C. Zhu, W. Z. Wang, L. Y. Liu, H. L. Jiang, B. Du, Q. Wei, Sens. Actuator B-Chem., 2014, 191, 605-611.

36 X. X. He, J. Zhang, X. G. Liu, L. Dong, D. Li, H. Y. Qiu, S. C. Yin, Sens. Actuator B-Chem., 2014, 192, 29-35.

37 S. Barman, M. Sadhukhan, J. Mater. Chem., 2012, 22, 2183221837. 